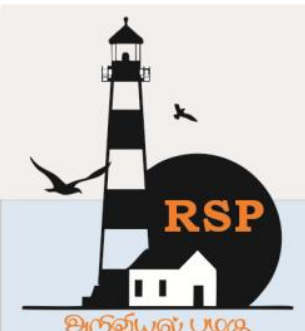

INTERNATIONAL RESEARCH JOURNAL ON ADVANCED SCIENCE HUB

Special Issue of First International Conference on Engineering, Science, and Technology (ICEST 2021)

\title{
Assessment of water reuse potential of wastewater treatment systems used in Mumbai, India
}

Ar. Nayana Raut ${ }^{1}$, Dr. Shashidhar R Kashyap ${ }^{2}$

${ }^{1}$ Rachana Sansad's Institute of Environmental Architecture, Mumbai, India; VIVA School of Architecture, Virar, Maharashtra, India

${ }^{2}$ Associate Professor, Rachana Sansad's Institute of Environmental Architecture, Mumbai, Maharashtra, India

nayanavishalraut@vivaarch.org

\begin{abstract}
Ever growing population of Mumbai has put additional pressure on existing infrastructure in terms of huge demand for portable water as well as treatment of city's waste water. Study aimed at review of city's wastewater in order to understand the reality of treatment quality of wastewater, it's reusability in terms of offsetting growing water demands of domestic, industrial and agricultural fields in and around the city. Literature review and case study method was used in order to get primary as well as secondary data for achieving data regarding overall functioning and water balance of the city. Because of lot of irregularities, current wastewater management systems are asking for paradigm shift from current centralized wastewater treatment systems to decentralized wastewater treatment systems. Conventional treatment systems treat wastewater as a 'waste' yet there is some reuse potential. Concept of collecting water and wastewater separately for better treatment, increased reuse potential, savings upon energy and better nutrient recovery can be used in order to move towards more ecologically and economically sound waste water management systems. To demonstrate this idea documentary and discourse analysis is used. The paper starts by providing general overview about water scarcity and security in India and then proceeds to provide comparative analysis between centralized and decentralized treatment systems used in the city in order to identify it's water reuse potential. Second, legislative and policy framework used in the city for wastewater treatment and management which is then followed by outline of the current situation and reflections on system dynamics in City. Third, the paper ends with a discussion on practical implications, policy options and conclusion. The presented study gives conceptual model based on Net Zero concept which can be helpful in making of sustainable future cities.
\end{abstract}

Keywords: Waste water Treatment Systems; Net zero approach; Water resource management; Water reuse potential; Nutrient recycling

\section{Introduction}

Water is a scarce natural resource which is fundamental to life, livelihood, food security and sustainable development. India has more than 18 $\%$ of the world's population, but has only $4 \%$ of world's renewable water resources and $2.4 \%$ of world's land area. Availability of utilizable water will be further under strain in future due to growing population and rising needs of nation posing serious challenges to water security. (National Water Policy, 2012) Apart from inadequate water supply; quality of water is a serious concern which is seriously affecting the health of the rural population due to pollution of water bodies with untreated or partially treated sewage and untreated industrial effluent. It has 
been reported that $70 \%$ of water consumed by rural population does not meet WHO standards. Major cities of India are generating on an average sewage of 38354 Million litres per day (MLD) whereas treatment capacity is only of 11786 MLD. Performance of state owned Sewage treatment plants(STP's), common effluent treatment plants(CETP's) does not meet the standards. Among the metropolitan cities, Delhi and Mumbai has highest i.e $26 \%$ of total capacity of sewage generated. (CPCB, 2013)

There is a National Framework Law as an umbrella statement of general principles governing the exercise of legislative and/or executive (or devolved) powers by the Centre, the States and the local governing bodies which aims at recognition of water not only as a scarce resource but also as a saviour of life and ecology. Therefore, water, particularly, groundwater, needs to be managed as a community resource held, by the state, under public trust doctrine to achieve food security, livelihood, and equitable and sustainable development for all. So, there is a serious need to identify and fix problem areas in order to achieve target of Sustainable Future Cities.[1-5]

Focus of the study is to evaluate existing wastewater treatment technologies used in the city for finding out difficulties in working of the technology, suggesting the scope of improvement for efficient use of technology and formulating tailor made solution to suit the technology to our macro as well as microclimatic conditions.

\section{Overview of Mumbai's water sector}

Since Mumbai is financial capital of India - a powerhouse of Indian economy; it can be one of the good case studies in terms of understanding water related issues in an urban sector. As per White paper report of Mumbai Municipal Corporation 2009, current total water supply to Mumbai is 3350 MLD (million litters per day) which includes water supply to bulk users, commercial enterprises, industrial uses and linkages.

Apart from this MCGM has also thought about extraction of ground water table as well as extra make up water through construction of new dams to fill demand and supply gap as well as to fulfil future needs. City has three layer of distribution system i.e. primary system from Main reservoirs/dams to balancing reservoirs, secondary system i.e. from balancing reservoirs to service reservoirs and lastly tertiary system i.e. service reservoirs to distribution network. Though this complex distribution networking is successfully done, system is mismanaged and misused through unmetered and unaccounted water supply.

Since water once used is called as wastewater; city's enormous domestic as well as industrial wastewater is another area of concern. Due to vertical expansion of the city a small piece of land generates huge amount of wastewater which has put additional pressure on sewerage network as well as treatment plants.

Mumbai is divided into seven sewerage zones for collection, conveyance and disposal of sewage. Each zone has it's own operating system which comprises of sewerage collection, conveyance system, pumping stations, rising mains, treatment and disposal facilities. Still sewage from city, extended suburbs and slums flows into storm water drains due to rapid expansion, development, dense population and non-accessibility to sewerage network. Existing sewage treatment plants are ineffective as they are not capable of taking this additional volume of wastewater. On top of it part of this sewage percolates into the ground resulting in contamination of ground water table. Water table in Mumbai is very high and has got contaminated due to mixing of untreated sewage. It has severe effect on the health of the city and marine resources. Considering the expected population growth increasing coverage of wastewater treatment is a must.

The least square regression shows the positive correlation of sewage with population, industrial units and health care institutions. The sewage generation will still rise in future because of growth of urbanization and industrialization. Therefore Municipal Corporation must increase the sewage treatment capacity and do the budgetary provisions through issue of debt instruments. Environmental education, behavioural change among people will help to reduce the sewage generation. Another problem which needs attention is lack of interest from authorities in sufficient investment in sewage networks. It is observed that investment in water sector is double as compared to sanitation sector. (Hingorani, 2011) So, it is better to invest in sanitation for achieving holistic solution in water sector.[6-9] 


\subsection{Integration of decentralized wastewater treatment system}

City has century old sewerage system which cannot be altered entirely to meet needs of ever growing population of the city. To lessen the load on existing centralized treatment plants, on-site treatment of sewage became mandatory requirement for all big scale construction projects. As per EIA notification, 2006 Environmental clearance is compulsory for Buildings and Construction Projects which has built up area > 20000 sq.m and <150000 sq.m. and for Town and Area Development Projects which is covering an area of $>_{-} 50 \mathrm{Ha}$ and or Built up area of $>_{-} 150000$ sq.m. It is therefore essential to reduce surface and ground water use in all sectors of consumption, to substitute fresh water with alternative water resources and to optimize water use efficiency through reuse options. Gupta et al., (2004) predicted that recycled wastewater will meet $15 \%$ of total water requirement in 2050. Municipal Corporation of Greater Mumbai (MCGM) is first to make Environmental clearance compulsory for high rise residential buildings in Mumbai. (i. e for buildings exceeding above $50 \mathrm{~m}$ height) which makes onsite treatment of sewage as compulsion. At the same time additional incentives are being provided through various rating systems for better implementation of the system. Due to unique geographical conditions, high population density and eventually high volume of wastewater to be treated city selected aerobic treatment plants due to it's efficiency in treatment within comparatively lesser space.

\section{Need of the study}

Wastewater reuse is an important component of both wastewater management and water resource management which offers an environmentally sound option for managing wastewater that dramatically reduces environmental impacts associated with discharge of wastewater effluent into surface waters. In addition, reuse provides an alternative water supply for many activities that do not require potable quality water and as such, permits the saved potable water to be used elsewhere.(WHO, 2006)

In water scarce environments, wastewater reuse and reclamation are often considered as a viable option for increased water resources availability. (Godfrey et al., 2006) Despite of the benefits associated with the reuse of the treated water, there are some challenges such as lack of knowledge, unawareness about reuse standards, and potential risk to public health, etc. affecting implementation of water reuse projects. So, there was a need to understand current status of problems associated with design and working of centralized and decentralized wastewater treatment systems as well as to identify reuse potential of treated wastewater from both type of treatment systems.

\subsection{Identifying reuse potential of Decentralized Wastewater Treatment Systems}

Since centralized treatment system is very difficult and expensive to reach every user in terms of it's sewerage network; decentralized treatment systems have now become need of the hour. The goal of a more sustainable wastewater management system is to use less energy, allow for the elimination or beneficial use of bio-solids, and restore natural nutrient cycles.(Diagger and Crawford, 2005), (Chalise A.,2014) The operation of the treatment system should have no or minimum effects on the natural cycles such as carbon, nitrogen and phosphorus. Any interaction could disturb these cycles and cause nonrecoverable impacts (IIPC, 2007).

Aerobic treatment systems are claiming it's effectiveness in efficient treatment of wastewater at comparatively higher cost for working as compared to conventional systems but at reduced environmental and social cost. "It is not always possible to design a wastewater treatment that minimises cost, energy use and land area, while maximizing performance. Therefore, one objective can be improved only at the expense of others, thus indicating the trade-offs between the different objectives." (Balkema, et.al, 2002)

So, there was a need to find out efficiency of the existing treatment systems in terms of it's reuse potential so that entire treated water can be used as an alternative source of water for non-domestic purposes such as flushing, landscaping, irrigation.

\subsection{Design of the study}

Three most popular treatment systems were selected namely MBBR (Moving Bed biological Reactor), MBR (Membrane Bioreactor) and SBR (Sequential Batch Reactor). Two case studies of each system were identified using snowball technique. For thorough understanding of these technologies each one is explained in detail. 


\section{www.rspsciencehub.com}

Primary data collection for validating the selected criteria's is done through conducting case studies through structured and unstructured interviews with the help of questionnaire.Secondary data regarding working of the system was acquired through literature review. The sample size of case studies in Mumbai is limited to access to information.

\subsubsection{Discussion and Findings}

Since all the aerobic treatment systems are comparatively new; a brief description about the systems and findings of the study are presented below:

\section{- Membrane Bio-reactor Technology}

This technology Combines the aeration and secondary clarifier in one and the same tank by sucking out the aerated mixed liquor through membranes instead of settling in a separate downstream tank and to that extent, it does yield a treated sewage with practically no BOD and suspended solids and hence being clear and virtually transparent besides its claimed ability to hold and sustain mixed liquor suspended solids (MLSS) of three to four times than what is possible in the conventional aeration tanks which in turn offers minimization of the footprint of the treatment plant. Diffused aeration is of course needed. There are different types of membranes as flat sheet, cross flow, dead end flow etc, which makes it difficult for common validated standard design criteria. (Ministry of Urban Development, GOI, 2012)

Findings of the Case study:

$>$ Though the system is very compact and claims to be very effective in terms of complete treatment of sewage which is best suited for the urban use; during visit system showed failure in terms of treatment of wastewater due to low Mixed Liquer Suspended Solids(MLSS) in the influent leading to scaling of the membranes.

$>$ Since system failed in treatment of wastewater influent to desired CPCB standards of water reuse; entire treated water (partially treated was left to the Municipal sewerage system.

- Moving Bed Bioreactor (MBBR):

MBBR is also called as FAB reactor
Volume 03 Issue $01 S$ January 2021

(fluidized- attached growth biological) treatment system. The media on which the bacterial growth takes place is kept in fluidized state by aeration. Influent is continuously fed to the reactor and the treated effluent is discharged from the system by overflow which has specific gravity less than water provides surface area for the growth of microorganisms. The Media fluidization is by virtue of hydraulic currents set by Aeration. The Media has high specific Surface Area, typically $400-500 \mathrm{~m} 2$ / m3. Air Grid System, which ensures high oxygen transfer efficiency to meet the oxygen demand exerted by the microorganisms and the fluidized state of the media. The high concentration of bacterial growth on the media hastens the process of $\mathrm{BOD} / \mathrm{COD}$ treatment thereby making the system very compact as compared to conventional Anaerobic treatment systems. Generally two stages are sufficient to achieve the desired reduction. The system comprises of the following main units: a) FAB reactor tank -I , b) FAB reactor tank - II c) Tube Settler (Thermax LTD wastewater services,n.d)

\section{Findings of the Case study:}

$>$ During visit it was observed that fluidized state of media helps in achieving desired treated water CPCB reuse standards under varied hydraulic loading conditions but it requires comparatively larger space for the entire setup comprising of reactor tanks, settling tank, pressurized sand filter and activated carbon filter.

$>$ It was observed that part of the treated water was used for flushing purpose after ozone treatment and some part of it was used for landscaping purpose and rest of it was left into municipal sewerage system.

\section{- Sequencing Batch Reactor Technology (SBR) :}

It differs from activated-sludge plants because it combines all of the treatment steps and processes into a single basin, or tank, whereas conventional facilities rely on multiple basins. This variant of ASP technology is essentially a batch treatment by combining, primary settling, aeration, secondary settling and decanting the treated sewage in a series of sequenced and or simultaneous reactions in the same basin on a time deferred cycle. Thus, multiple basins are used whereby when one basin 


\section{www.rspsciencehub.com}

is in one part of the cycle such as aeration, another tank will be settling and discharging the treated sewage in a cyclically repeated operation. (Ministry of Urban Development, GOI, 2012)

Findings of the Case study:

$>$ During visit it was observed that due to treatment of influent in batch-wise and cyclic manner; system efficiently treats influent to the CPCB treated water reuse standards in a single tank which also gives flexibility in terms of adding multiple such units for additional treatment capacity.

$>$ It was observed that part of the treated water was left into municipal sewerage system.

\subsection{Identifying Reuse potential of Centralized} Treatment plant

Conventional wastewater solutions, including water flush toilets, combined sewerage, and centralised treatment, did not lead to an integrated solution. Centralized wastewater treatment leads to mixing of the different wastewater streams resulting in dilution of wastewater containing pathogens, toxic components such as heavy metals, organic micro pollutants which makes treatment more complex and requires higher levels of resources such as energy, money, space, and expertise, still posing pressure on the environment through emissions.

Water-borne sewerage is a waste disposal paradigm that works neither for the poor nor for poor nations and settlements. This paradigm is extremely expensive because it has high economic costs, environmental and public health costs and, as a result, high political costs. (Balkema, et.al, 2002) So, there was a need to look into treatment efficiency and reuse potential of centralized treatment plants used for taking care of city's sewage treatment.

\subsubsection{Design of the study}

Since Centralized sewage treatment is a huge investment in terms of economical, social as well as environmental point of view; it's effectiveness of the treatment as well as it's reuse potential need to be understood in order to offset city's water needs. Performance of the treatment plants was reviewed with the help of performance assessment report carried out by Ministry of Environment and Forest (MoEF) in the year 2007.

Since Aerobic treatment systems showed
Volume 03 Issue 01S January 2021

satisfactory performance at city level treatment of wastewater; physical case study of the same was also carried out in order to understanding it's working and reuse potential.

\section{Discussion and Findings}

For the performance assessment of centralized STP's of Mumbai, 4 STP's were selected for the audit. Observations mentioned in the report are as follows:

- Marine out fall at Bandra (1500MLD i.e million litre per day) for treating wastewater generated in Bandra zone:

As per the report the plant is working well;meeting design standards for bio assay test on fish with $100 \%$ survival in 96 hours as per consent given by SPCB(State pollution Control Board). But after treatment treated water is thrown into the sea, hence no reuse of wastewater was observed.

- Aerated lagoon at Versova (90 MLD) (2 streams of 45MLD each for treatment of wastewater generated in Versova zone, 1998: One stream fully aerated, second is partially mixed facultative reactor and the third lagoon acts as a polishing pond)

Findings of the report state that de-sludging of the plant need to be done in order to avoid foul smell in the plant campus. Otherwise plant is giving satisfactory performance in terms of meeting CPCB treated water discharge standards for removal of BOD(Biological Oxygen Demand) and SS(Suspended Solids). Since treated water is discharged into the adjoining creek, there is no reuse of treated water.

- Aerated lagoon at Ghatkopar (300MLD) (4 nos. of 75 mld each in parallel constructed in 2003) for treating wastewater generated in Ghatkopar area)

Findings of the report states that only 230 MLD of wastewater is being received for treatment and the STP is thus it is underutilized. Inlet chamber at the STP was found overflowing which appeared to be on account of too much silt deposition in the chamber which needs to be cleaned regularly. Treated effluent is meeting the design standards for BOD \& SS. Since treated effluent is being discharged into the Thane creek through an open channel; there is no reuse of treated water.

- Aerated lagoon at Bhandup (280MLD) (4 nos. of 70 mld each in parallel constructed 
in 1998) for treating wastewater generated in Bhandup area)

Findings of the report states that totally 280 mld of wastewater is being received for treatment and the STP is thus it is fully utilized. One of the lagoons was not in use due to damage of the treated effluent pipe. Treated effluent is meeting the design standards for BOD \& SS.Some part of the treated effluent is used for watering the plants after chlorination treatment and rest of the treated effluent is being discharged into the Thane creek through an open channel.

- Sequencing Batch Reactor Plant at Nerul (100 - 250 MLD): Designed for Centralized domestic sewage treatment of Nerulbased on Cyclic Activated sludge process

Findings of the case study are mentioned below: Though plant treats huge amount of city's wastewater there were no traces of odour throughout the entire plant except at raw water tank. Plant does not need much of the skilled and unskilled labour. Only two PLC operators and six unskilled labours are sufficient to operate entire plant. MPCB reports were checked to find out effectiveness of technology in terms of treating wastewater. It has given very good effluent quality.

Sludge handling was done very much sophistically with proper disinfection measures. But sludge reuse was totally neglected. Entire sludge was dumped at back of the plant which may cause adverse effects on the environment.

There are no plans thought off for reuse of treated water. All the treated water is thrown off in the creek.

\section{Planning and Implementation of Wastewater Reuse}

Though wastewater is 'once used water'; it has lot of reuse potential in terms of fulfilling our day to day needs of water for non-domestic purposes such as irrigation, landscaping and flushing. Since enforcement of law is not there people are hesitant to accept treated water for reuse applications. Knowing current pressing needs of water; there is a need to create awareness amongst the people regarding the valuable asset that they have i.e treated water.

Grey water, treated domestic wastewater is quite safe to reuse for non- domestic purposes.
Despite the fact that wastewater reuse has been implemented in many countries, different reuse projects have failed due to the absence of thorough preliminary investigations or feasibility study which involves detailed studies of the proposed project and its implications on the society. So it is very essential to identify user friendly and appropriate technology which proves to be sustainable in that particular region as well as socio-cultural context.

Unregulated wastewater reuse has been in practice for centuries in many parts of the world. However, the concept of integrated wastewater reuse has received increased attention nowadays due to number of factors namely, increasing demand for fresh or portable water for domestic, agricultural and industrial purposes, high cost of portable water in terms of it's availability, distribution and it's environmental impact, degradation of freshwater resulting from improper disposal of wastewater and growing demand for greener strategies for water conservation.(WHO,2006)

Planning and implementation of waste water reuse is possible in following areas:

- Storm water as well as Rainwater as a reuse source:

Rainwater in the form of storm water and rooftop water has great reuse as well as ground recharge potential due to negligible amount of impurities in the water. Due to combined sewerage system and absence of separate storm water drains in the city; entire rainwater also flows into the sewerage system increasing tremendous amount of pressure on centralized wastewater treatment cost due to increased quantity of wastewater as well as due to dilution of sewage leading to ineffectiveness in the treatment due to shock loading.

$>$ Planning and Implementation:

Separate sewerage system need to be established in order to avoid entry of rainwater into sewerage system and strategies need to be adopted for harvesting of rainwater wherever possible.

$>$ Grey water as a reuse source:

Planning and Implementation: Greywater constitutes about $70 \%$ of household water 
Consumption and has lower concentration of organic compounds

and fewer pathogens compared to domestic wastewater. As a result, greywater may be treated and reused much easily than composite domestic wastewater for the point of treatment technologies applied and relevant costs (Sachin, 2015). Greywater constitutes about $70 \%$ of household water consumption and has lower concentration of organic compounds and fewer pathogens compared to domestic wastewater. As a result, greywater may be treated and reused much easily than composite domestic wastewater for the point of treatment technologies applied and relevant costs (Sachin, 2015). Greywater constitutes about $70 \%$ of household water consumption and has lower concentration of organic compounds and fewer pathogens compared to domestic wastewater. As a result, greywater may be treated and reused much easily than composite domestic wastewater for the point of treatment technologies applied and relevant costs (Sachin, 2015).Greywater is generally defined as "Low polluted wastewater originating from bathtubs, showers, wash basins and washing machines excluding wastewater from toilet flushing system" (Kraume et al., 2010). Greywater constitutes about $70 \%$ of household water and has lower concentration of organic compounds and fewer pathogens compared to domestic wastewater. As a result, grey water may be treated and reused much easily than composite domestic wastewater due to lesser treatment requirement and ultimately treatment at lesser cost. (Couto et al., 2015), (Kraume et al., 2010)

\section{- Planning and Implementation:}

Since there is no point in mixing grey water i.e lesser affected water into severely affected water i.e blackwater; necessary separation of it need to be done at the point of generation with the help of two pipe system so that it can be reused effectively with lesser treatment or no treatment depending upon the reuse application which will ultimately reduce load on decentralised or onsite treatment systems and intern will reduce load on centralized sewerage system.

- Treated wastewater as a reuse source:
Waste water if treated to meet CPCB reuse standards; can be a good alternative source of water for non portable uses such as flushing, landscaping at household level, for irrigation in agricultural practices and for fulfilling industrial water needs.

\section{- Planning and implementation:}

For efficient reuse of treated water for flushing purposes two pipe system (dual pipe) should be in place, for reuse in landscaping, irrigation network should be established and for reuse of water for irrigation as well as industrial purposes in agricultural water can be sold to farmers and industries at comparatively cheaper prices in water scarce region around the city limits.

\section{Conclusion}

This report is a review of existing centralized as well as decentralized treatment technologies used in Mumbai city for treating huge amount of city's wastewater. It is apparent that there is some amount of policy enforcement in terms of compulsion for onsite treatment or decentralized treatment of wastewater in order to avoid end-of-pipe solution which is helping city to complete incomplete sewerage network. Aerobic treatment technologies such as sequencing batch reactor has proved to be very effective technology in urban context due to it's compact nature, treatment efficiency, nutrient recycling potential, capacity to tackle various hydraulic loads and it's capacity to treat wastewater quantities of KLD to MLD i.e household level to city level in order to achieve net zero target of 'Sustainable Future Cities'.

There are sufficient researches available on sustainability Assessment of treatment technologies which will help planners to take a decision about adoption of appropriate technology for achieving effective water treatment and reuse; since there always exists a trade-off between cost of treatment and it's environmental, social impacts. After weighting all the impacts one can decide upon the selection of technology for the desired purpose. This report examined existing issues with reuse of treated wastewater at 
www.rspsciencehub.com

household level as well as at city level to realize potential of sustainably fulfilling city's own water needs with net zero approach with the help of proper monitoring and auditing systems based on 'Polluter pays principle."

\section{Acknowledgement (Optional)}

I would like to thank Dr. Kashyap (Associate Professor, RachanaSansad's Institute of Environmental Architecture, Mumbai) for his valuable guidance and support for carrying out this research.

\section{References}

[1].Chalise, AnupamaRegmi, 2014. "Selection of Sustainability Indicators for Wastewater Treatment Technologies," n.d., 147.

[2].CPCB, 2007 ,Evaluation Of Operation And Maintenance Of Sewage Treatment Plants In India

[3].Couto E. A., Calijuri M. L., Assemany P. P., Santiago A. F., \& Lopes L. S. (2015): Greywater treatment in airports using anaerobic filter followed by UV disinfection: an efficient and low cost alternative. Journal of Cleaner Production, 106: 372-379.

[4].Daigger, G. T., and G.V. Crawford.(2005). Wastewater Treatment Plant of the FutureDecision Analysis Approach for Increased Sustainability.2nd IWA Leading-Edge Conference on Water and Wastewater Treatment Technology, Water and Environment Management Series. London, 361-369, U.K.: IWA Publishing

[5].IPCC.(2006). IPCC Guidelines for National Greenhouse Gas Inventories.Inst. for Global Environ. Strategies, Hayama, Japan. Intergovernmental Panel on Climate Change

[6].Kraume M., Scheumann R., Badan A. \&, Hamouri B. E. (2010): Performance of a compact submerged membrane sequencing batch reactor (SM-SBR) for grey water treatment. Desalination, 250: 1011-1013.

[7].National Water Policy, 2012

[8].WHO, World Health Organization (2006).Guidelines for the safe use of wastewater excreta and greywater- Policy and regulatory aspects Vol. 1, Geneva, Switzerland.

[9]. Vleuten-Balkema, Annelise Juliana van der. Sustainable Wastewater Treatment: Developing a Methodology and Selecting
Volume 03 Issue 01S January 2021

Promising Systems. Eindhoven: Univ. Press, 2003. 